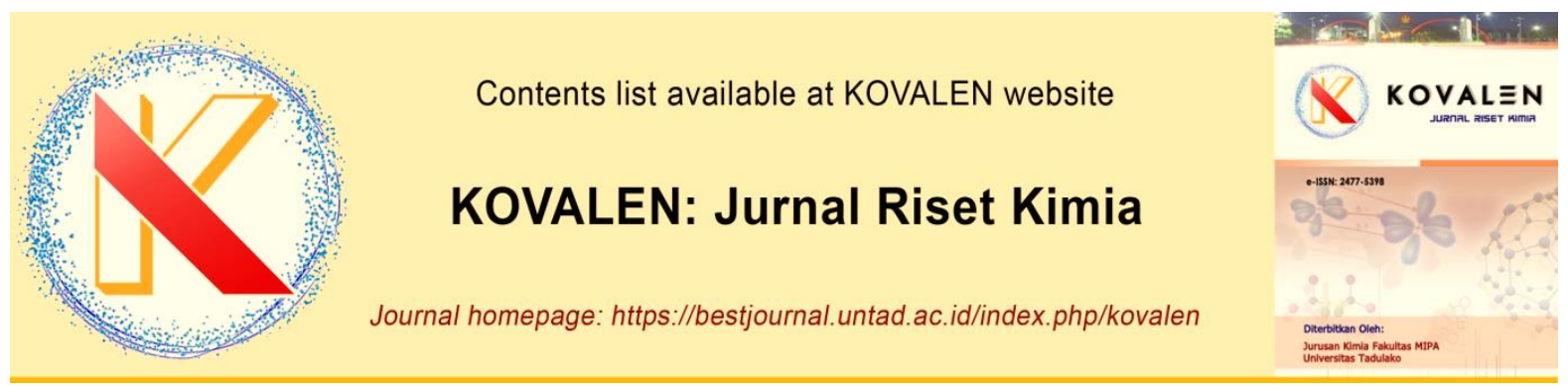

\title{
Mikroenkapsulasi Ekstrak Kulit Buah Naga Super Merah (Hylocereus costaricensis) pada Berbagai Massa Maltodekstrin dan Aplikasinya Sebagai Antioksidan
}

\section{[Microencapsulation of Super Red Dragon Fruit (Hylocereus costaricensis) in Various of Maltodextrin Mass and its Application as an Antioxidant]}

\author{
Sucianti ${ }^{*}$ Nurhaeni, Jaya Hardi \\ Jurusan Kimia, Fakultas Matematika dan Ilmu Pengetahuan Alam, Universitas Tadulako, \\ Jl. Soekarno-Hatta Km. 9, Kampus Bumi Tadulako, Palu, Indonesia \\ ${ }^{*}$ Corresponding author: sucianti2428@gmail.com
}

\begin{abstract}
Red super dragon fruit peel (Hylocereus costaricensis) extract has capability to scavenge DPPH and the activity could be maintained by using maltodextrin as coating. The aims of the research are to determine ratio of red super dragon fruit peel ethanol extract toward maltodextrin producing microcapsule with the highest coating efficiency and DPPH scavenging content by microcapsule of red super dragon fruit peel extract. Microencapsulation was carried out using freeze-drying technique. Comparison of red super dragon fruit peel extract and maltodextrin were 1:8,1:10,1:12 and 1:14 $(\mathrm{w} / \mathrm{w})$. The results show that the highest efficiency ratio of coating extract of red super dragon fruit peel with maltodextrin was 1: 8 with percentage of $90,77 \%$. Level of DPPH scavenging content of red super dragon fruit peel extract microcapsule with ratio of $1: 8$ on 5 minutes and 60 minutes each is $27.36 \%$ and $46.62 \%$.
\end{abstract}

Keywords: Hylocereus costaricensis, freeze-drying, maltodextrin, microencapsulation

\begin{abstract}
ABSTRAK. Ekstrak kulit buah naga super merah (Hylocereus costaricensis) memiliki kemampuan untuk menghambat DPPH dan aktivitasnya dapat dipertahankan dengan cara melakukan penyalutan menggunakan maltodekstrin. Penelitian ini bertujuan untuk mengetahui rasio ekstrak etanol kulit buah naga super merah terhadap maltodekstrin yang menghasilkan mikrokapsul dengan efisiensi penyalutan tertinggi dan mengetahui persen penghambatan DPPH oleh mikrokapsul ekstrak kulit buah naga super merah. Mikroenkapsulasi dilakukan dengan menggunakan teknik pengeringan beku. Perbandingan ekstrak kulit buah naga super merah dan maltodekstrin yaitu 1:8, 1:10, 1:12, dan 1:14 (b/b). Hasil penelitian menunjukkan bahwa efisiensi penyalutan ekstrak kulit buah naga super merah dengan maltodekstrin yang diperoleh tertinggi pada rasio $1: 8$, yaitu $90,77 \%$. Tingkat persen peredaman DPPH tertinggi untuk mikrokapsul ekstrak kulit buah naga super merah diperoleh pada rasio 1:8 pada menit ke-5 dan ke-60 masing-masing 27,36\% dan 46,62\%.
\end{abstract}

Kata kunci: Hylocereus costaricensis, pengeringan beku, maltodekstrin, mikroenkapsulasi

Riwayat artikel: Diterima 23 Maret 2018, Disetujui 27 November 2020

Cara sitasi: Sucianti., Nurhaeni., \& Hardi, J. (2020). Mikroenkapsulasi Ekstrak Kulit Buah Naga Super Merah (Hylocereus costaricensis) pada Berbagai Massa Maltodekstrin dan Aplikasinya Sebagai Antioksidan. KOVALEN: Jurnal Riset Kimia, 6(3): $191-197$. DOI: https://doi.org/10.22487/kovalen.2020.v6.i3.9889

\section{LATAR BELAKANG}

Buah naga (Dragon fruit) sejatinya merupakan tanaman kaktus (famili Cactaceae).
Tanaman ini berasal dari Meksiko, Amerika Tengah, Amerika Selatan bagian utara (Colombia). Saat ini buah naga telah banyak 
dibudidayakan di berbagai daerah di Indonesia. Sekitar $30-35 \%$ bagian buah naga merupakan kulit buah yang seringkali hanya dibuang sebagai limbah. Kulit buah naga memiliki warna yang menarik yakni merah keunguang. Warna tersebut disebabkan karena adanya kandungan pigmen antosianin pada buah tersebut (Putri et al., 2015).

Kestabilan pigmen antosianin dapat dipengaruhi oleh beberapa faktor seperti $\mathrm{pH}$, enzim, cahaya, oksigen, suhu, oksidator, penyimpanan. Antosianin stabil pada $\mathrm{pH} 3,5$ dan suhu $50^{\circ} \mathrm{C}$ mempunyai berat molekul $207,08 \mathrm{gram} / \mathrm{mol}$ dan rumus molekul $\mathrm{C}_{15} \mathrm{H}_{110}$ (Fennema, 1996). Untuk mengatasi ketidakstabilan antosianin yang disebabkan pengaruh lingkungan tersebut maka dapat dilakukan teknik mikroenkapsulasi untuk meminimalisir pengaruh lingkungan terhadap stabilitas ekstrak kulit buah naga super merah.

Mikroenkapsulasi adalah proses penggunaan penyalut yang relatif tipis pada partikel-partikel kecil zat padat atau tetesan cairan dan dispersi zat cair dengan ukuran partikel berkisar antara 1-1000 mikrometer (Trojer, 2012). Mikrokapsul sebagai hasil dari proses mikroenkapsulasi memiliki stabilitas yang lebih baik (Lachman et al., 1994).

Berdasarkan penelitian sebelumnya, pigmen dari bunga rosela yang telah dienkapsulasi memiliki stabilitas yeng lebih baik dibandingkan dengan pigmen yang tidak dienkapsulasi. Dimana pigmen yang dienkapsulasi dapat bertahan selama 105 hari pada suhu penyimpanan $37^{\circ} \mathrm{C}$ (Idham et al., 2012). Sementara itu berdasarkan penelitian yang dilakukan oleh (Comunian et al., 2013), stabilitas asam askorbat yang dienkapsulasi lebih baik dibandingkan dengan asam askorbat yang tidak dienkapsulasi. Dimana setelah penyimpanan pada hari ke 30 pada suhu $20^{\circ} \mathrm{C}$ asam askorbat yang tidak dienkapsulasi menunjukkan kadar $0 \%$ sedangkan asam askorbat yang dienkapsulasi menunjukkan kadar 57-80\%. (Hardi et al., 2020) telah melakukan enkapsulasi ekstrak kulit buah naga super merah dengan variasi kecepatan pengadukan dan memperoleh efisiensi penyalutan pada rasio ekstrak berbanding maltodekstrin 1:4 (b/b) memiliki nilai tertinggi, yaitu $66,85 \%$ dengan diameter ukuran partikel $14,24 \mu \mathrm{m}$. Nilai efisiensi tersebut masih dapat ditingkatkan dengan melakukann variasi rasio maltodekstrin terhadap ekstrak kulit buah naga super merah. Hasil mikrokapsulasi selanjutnya dapat diaplikasikan sebagai antioksidan.

\section{METODE PENELITIAN}

\section{Bahan dan Peralatan}

Bahan yang digunakan pada penelitian ini yakni kulit buah naga super merah (Hylocereus costaricensis), aquadest, etanol $96 \%, \mathrm{HCl} 1 \%$, maltodekstrin, 1,1-difenil-2pikrilhidrazil (DPPH).

Peralatan yang digunakan pada penelitian ini yakni aluminium foil, blender, ayakan 60 mesh, neraca analitik, mesin agitasi, reaktor berpengaduk, rotary vacum evaporator, oven, pengering beku (Freeze Dryer), spektrofotometer UV-Visibel PerkinElmer L850, scanning electron microscopy (SEM) HITACHI FLEXSEM 100.

\section{Prosedur Penelitian}

\section{Ekstraksi kulit buah naga super merah}

Sebanyak $500 \mathrm{~g}$ kulit buah naga super merah dimaserasi menggunakan pelarut etanol $96 \%$ dan $\mathrm{HCl} 1 \%$ dengan perbandingan volume $9: 1$ sebanyak $1000 \mathrm{~mL}$ selama $1 \times 24$ jam pada suhu ruang, kemudian disaring dan filtratnya ditampung. Filtrat yang diperoleh diuapkan 
dengan rotary vacuum evaporator pada suhu $40^{\circ} \mathrm{C}$ sehingga didapatkan ekstrak kental (Putri et al., 2015).

\section{Mikroenkapsulasi ekstrak kulit buah naga super merah}

Mikroenkapsulasi ekstrak kulit buah naga super merah dilakukan dengan menggunakan metode (Supriyadi \& Rujita, 2013) dengan beberapa modifikasi, $160 \mathrm{~g}$ maltodekstrin dilarutkan dengan aquades perbandingan (1:1). Kemudian ekstrak etanol kulit buah naga super merah ditambahkan kedalam larutan maltodekstrin sambil diaduk dengan reaktor berpengaduk pada suhu ruang dengan kecepatan 700 rpm selama 1 jam. Rasio antara ekstrak dengan maltodekstrin yaitu 1:8, 1:10, 1:12 dan 1:14 atas dasar berat/berat (b/b). Campuran mikroemulsi selanjutnya diubah menjadi mikrokapsul dengan menggunakan alat freeze-drying, serbuk yang didapatkan selanjutnya ditentukan efisiensi mikroenkapsulasi (Hardi et al., 2020).

\section{Analisis efisiensi mikroenkapsulasi (EM)}

Mikrokapsul digerus sebanyak $0,5 \mathrm{~g}$ dan diekstraksi dengan $10 \mathrm{~mL}$ etanol 96\%, kemudian disaring dan filtratnya dipekatkan dengan menggunakan radas penguap putar, ekstrak pekat yang diperoleh kemudian dioven dan ditimbang. Efisiensi mikroenkapsulasi ditentukan dengan menggunakan Persamaan 1 (Hardi et al., 2013).

$$
\operatorname{EM}(\%)=\frac{M m-M k x_{5}^{a}}{M e} \times 100
$$

Keterangan:

$\mathrm{EM}=$ =Efisiensi mikroenkapsulasi/penyalutan

$\mathrm{a} \quad=$ Massa mikrokapsul total $(\mathrm{g})$

$\mathrm{b} \quad=$ Massa mikrokapsul yang dianalisis (g)

$\mathrm{Mm}$ = Massa ekstrak mikrokapsul $(\mathrm{g})$

$\mathrm{Mk}=$ Massa kontrol (g)

Me = Massa awal ekstrak kulit buah naga (g)

Selanjutnya mikrokapsul dengan nilai efisiensi tertinggi ditentukan dengan morfologi dan ukurannya dengan menggunakan alat Scanning Electron Microscopy (SEM).

Peredaman DPPH menggunakan mikrokapsul ekstrak kulit buah naga super merah (Molyneux, 2003; Hardi et al., 2020).

Peredaman DPPH ditentukan dengan metode radikal bebas $\mathrm{DPPH}$. Larutan DPPH $0,002 \%$ dibuat dengan cara melarutkan kristal DPPH 0,002 g dalam $50 \mathrm{~mL}$ etanol 96\%. Kemudian dari masing-masing Bahan uji diambil 0,5 g mikrokapsul kulit buah naga merah supermerah, lalu dimasukkan kedalam labu ukur $10 \mathrm{~mL}$ dan dipipet sebanyak $200 \mu \mathrm{l}$ ke dalam kuvet, kemudian ditambahkan (reaksikan) larutan DPPH sebanyak $3 \mathrm{~mL}$, selanjutnya dibuat spektra sinar tampak (400$600 \mathrm{~nm}$ ). Pada menit ke-5 setelah pereaksian dibaca absorban pada 497-517-537 nm dan dilakukan kembali pada menit ke-60. Perhitungan absorbansi antiradikal bebas DPPH dan larutan uji ditentukan menggunakan persamaan 2, sedangkan aktivitas antiradikal bebas sebagai persentase peredaman menggunakan persamaan 3 :

Absorbansi Sampel $=A_{517}-\frac{\text { Abs 497+Abs } 537}{2}$

$\%$ Peredaman DPPH $=1-\frac{\text { Absorban sampel }}{\text { Absorban DPPH }} \times 100$

\section{HASIL DAN PEMBAHASAN}

\section{Ekstrak Kulit Buah Naga Super Merah}

Ekstraksi kulit buah naga super merah merupakan proses pemisahan kandungan kimia pada kulit buah naga super merah dengan bantuan pelarut organik. Metode ekstraksi yang digunakan yakni metode maserasi menggunakan pelarut etanol $96 \%$ yang diasamkan dengan $\mathrm{HCl} 1 \%$. Menurut (Putri et al., 2015) etanol merupakan pelarut yang memiliki senyawa yang bersifat polar dan non polar karena etanol memiliki gugus etil 
yang bersifat non polar dan hidroksi yang bersifat polar. Penambahan $\mathrm{HCl}$ dalam etanol dikarenakan senyawa antosianin bersifat stabil dalam suasana asam, sehingga saat proses maserasi dilakukan, akan menghasilkan kandungan antosianin pada kulit buah naga super merah secara optimal. Hasil maserasi $500 \mathrm{~g}$ kulit buah naga super merah yang telah halus dengan $5 \mathrm{~L}$ (500 mL × 5 kali maserasi) dengan etanol $96 \%$ yang diasamkan dengan $\mathrm{HCl} 1 \%$ dengan perbandingan volume $9: 1$ menghasilkan 86,4 g ekstrak kental etanol yang berwarna merah pekat.

\section{Efisiensi Mikroenkapsulasi}

Penghitungan efisiensi mikroenkapsulasi digunakan untuk mengetahui tingkat keberhasilan proses mikroenkapsulasi. Efisiensi yang dimaksud dalam penelitian ini adalah rasio antara ekstrak kulit buah naga dengan penyalut maltodekstrin.

Pada Gambar 1, dapat dilihat bahwa semakin tinggi rasio ekstrak kulit buah naga tersalut maltodekstrin, maka semakin rendah nilai efisiensi penyalutan yang dihasilkan. Efisiensi mikrokapsul ekstrak kulit buah naga tersalut maltodekstrin yang dihasilkan tiap rasio $1: 8,1: 10,1: 12$, dan 1:14 (b/b) masing-masing sebesar 90,77\%; 78,55\%; 63,53\%; dan $27,95 \%$. Semakin banyak jumlah bahan penyalut dibandingkan bahan inti, maka semakin rendah efisiensi penyalutan pada kulit buah naga. Penelitian yang dilakukan oleh (Febriyenti et al., 2013), yang menunjukkan bahwa ekstrak kulit buah naga tersalut gelatin pada rasio 1:1 memiliki efisiensi penyalutan $30,6 \%$ dan pada rasio $1: 2$ memiliki efisiensi penyalutan $20,6 \%$.

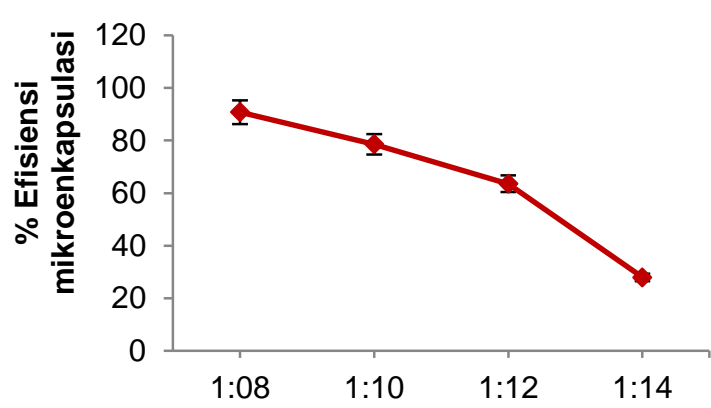

Rasio ekstrak : maltodekstrin (b/b)

Gambar 1. Pengaruh rasio ekstrak kulit buah naga : maltodekstrin terhadap efisiensi penyalutan

Jumlah penyalut yang digunakan dalam mikroenkapsulasi juga dapat mempengaruhi ukuran partikel yang dihasilkan. Semakin banyak jumlah bahan penyalut dibandingkan bahan inti maka ukuran partikel juga akan semakin besar karena terjadi peningkatan ketebalan dinding mikrokapsul yang terbentuk.

Adapun Menurut penelitian (Novaldi et al., 2019) mikroenkapsulasi oleoresin terhadap penyalut maltodekstrin yang mencapai efisiensi tertinggi pada rasio $1: 6$ (b/b) sebesar 55,04\%. Maltodekstrin sering digunakan karena memiliki sifat sebagai penyalut yang baik karena kemampuannya dalam membentuk emulsi dan viskositasnya yang rendah (Laohasongkram et al., 2011).

Berdasarkan data sidik ragam nilai efisiensi mikrokapsul ekstrak kulit buah naga super merah tersalut maltodekstrin dengan berbagai rasio memiliki nilai singnifikan $<\alpha$ $(0,05)$, maka perlakuan rasio berpengaruh nyata terhadap efisiensi penyalutan sehingga dilanjutkan dengan uji Duncan. Hasil uji lanjut Duncan menunjukkan bahwa rasio 1:8; 1:10; $1: 12$ dan rasio $1: 14$ berbeda nyata dengan nilai efisisensi pada penggunaan rasio 1:8 yang dinyatakan sebagai hasil terbaik $(90,77 \%)$. 
Morfologi Mikrokapsul

Pengamatan morfologi terhadap mikrokapsul ekstrak kulit buah naga dilakukan dengan menggunakan SEM (Scanning Electron Microscope). Hasil pengamatan marfologi mikrokapsul ekstrak kulit buah naga yang dilakukan dengan foto Scanning Electron

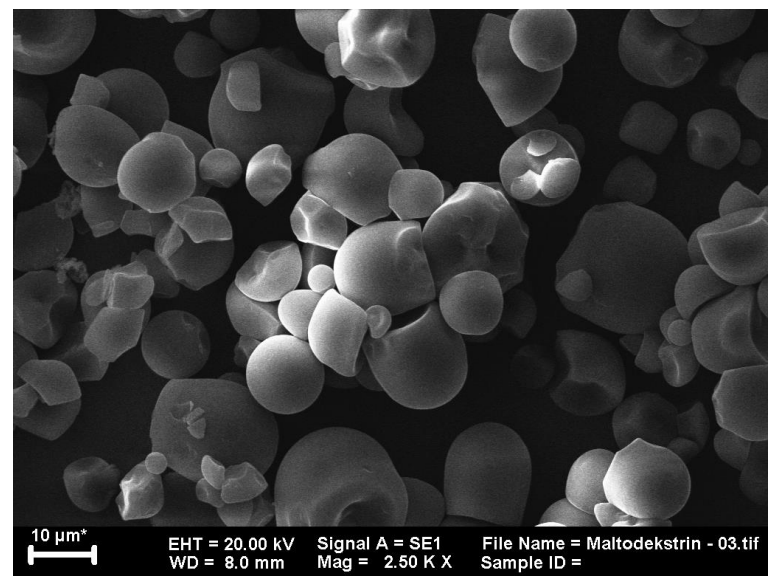

(a)
Microscope (SEM) pada perbesaran 1000 kali terlihat seluruh permukaan mikrokapsul yang tidak beraturan dengan tipe matriks (Gambar 2). Tipe matriks merupakan tipe mikrokapsul yang mengandung bahan inti yang terdispersi merata dalam bahan penyalutnya (Thies, 1996).

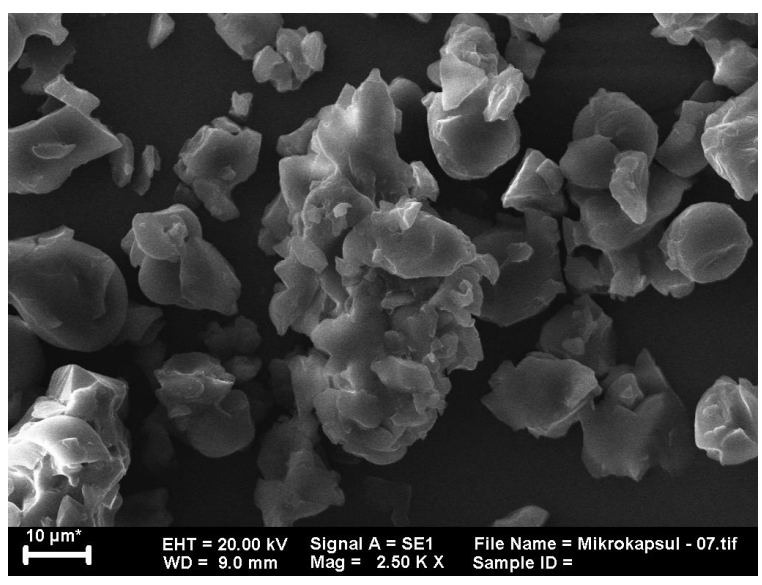

(b)

Gambar 2. Morfologi (a) maltodekstrin dan (b) mikrokapsul pada perbesaran 2500X.

Mikrokapsul yang didapatkan berbeda dengan penyalut maltodekstrin yang memiliki bentuk sferis dan cukup beraturan, hal ini kemungkinan pada proses pengadukan dengan kecepatan yang tinggi sehingga akan memecah partikel mikrokapsul dengan lebih kecil dengan bentuk yang tidak sferis. Hal lain yang dapat mengakibatkan bentuk tidak merata sferis ialah proses pengeringan beku. Pada saat proses pembekuan secara cepat dapat mengakibatkan terbentuknya kristal es yang dapat mempengaruhi bentuk dinding dari penyalut maltodekstrin (Fellows, 2017). Mikrokapsul memiliki berbagai macam bentuk antara lain ada yang berbentuk bulat sferis dan ada memiliki bentuk yang tidak beraturan.

Pada penelitan ini, hasil perhitungan partikel nilai rata-rata ukuran partikel mikrokapsul ekstrak kulit buah naga adalah $20,62 \mu \mathrm{m}$. Sedangkan ukuran partikel maltodekstrin adalah $13,55 \mu \mathrm{m}$. Secara keseluruhan hasil yang didapatkan telah memenuhi persyaratan untuk ukuran partikel

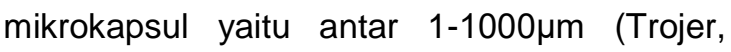
2012).

\section{Peredaman DPPH Menggunakan Mikrokapsul Ekstrak Kulit Buah Naga Super Merah Tersalut Maltodekstrin}

DPPH (Difenilpikril hidrazil) merupakan suatu senyawa radikal bebas yang berperan sebagai oksidator saat bereaksi dengan suatu antioksidan. Pengujian peredaman DPPH merupakan prosedur yang sederhana. Berdasarkan hasil pengukuran panjang gelombang maksimum DPPH $0,002 \% \mathrm{~b} / \mathrm{v}$ didapatkan panjang gelombang maksimum $517 \mathrm{~nm}$ dengan absorbansi 1,356. Berdasarkan persen peredaman yang diperoleh pada menit ke-5 dan ke-60 diperoleh suatu kurva hubungan antara \% peredaman dan 
konsentrasi suatu rasio mikrokapsul ekstrak kulit buah naga super merah (Gambar 3).

Pada Gambar 3 dapat di lihat bahwa pada menit ke-5 dari masing-masing rasio 1:8; 1:10; 1:12; dan 1:14 (b/b) nilai persen peredaman radikal bebas DPPH yaitu 27,35\%; 24,62\%; $20,66 \%$; dan $16,10 \%$; sedangkan pada menit ke-60 dari masing-masing rasio $1: 8 ; 1: 10 ; 1: 12$; dan 1:14 nilai persen peredaman radikal bebas DPPH yaitu 46,62\%; 40,19\%; 30,22\%; dan $23,79 \%$.

Persentase peredaman DPPH oleh mikrokapsul ekstrak kulit buah naga tersalut maltodekstrin tertinggi diperoleh pada rasio 1:8 baik pada menit ke-5 (27,35\%) maupun menit ke-60 (46,62\%) (Gambar 3). Sulastri (2016), melaporkan bahwa kulit buah naga super merah memiliki persentasi peredaman radikal bebas DPPH sebesar $79,24 \%$.

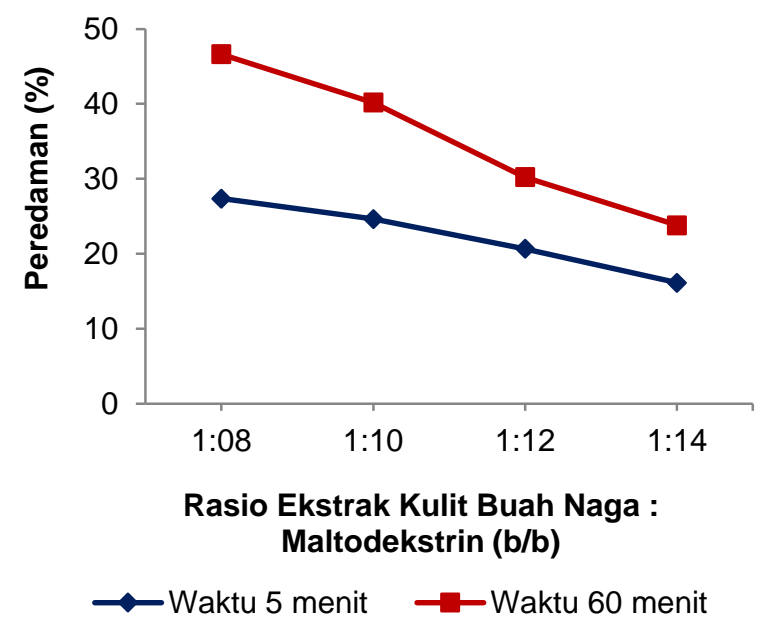

Gambar 3. Pengaruh rasio ekstrak kulit buah naga super merah tersalut maltodekstrin terhadap persen peredaman

Nurliyana et al. (2010) melaporkan bahwa dalam $1 \mathrm{mg} / \mathrm{mL}$ kulit buah naga super merah mampu menghambat $83,48 \pm 1,02 \%$ radikal bebas, sedangkan pada daging buah naga super merah hanya mampu menghambat 27,45 $\pm 5,03 \%$ radikal bebas. Kulit buah naga super merah memiliki persentase peredaman radikal bebas DPPH sebesar 79,24\%. Sedangkan menurut (Putri et al., 2015) ekstrak etanol kulit buah naga super merah menghasilkan 10,85 g ekstrak kental yang berwarna merah pekat dan aktivitas antioksidan peredaman optimum pada menit ke-5 sebesar $77,01 \%$ dan menit ke-60 sebesar $97,84 \%$.

\section{KESIMPULAN}

Ekstrak kulit buah naga super merah (Hylocereus costaricensis) dapat dienkapsulasi dengan maltodekstrin yang menghasilkan mikrokapsul dengan ukuran partikel 20,62 $\mu \mathrm{m}$ dan efisiensi penyalutan tertinggi pada rasio 1:8 sebesar 90,77\%, dan tingkat persen peredaman DPPH mikrokapsul ekstrak kulit buah naga super merah diperoleh pada rasio $1: 8$ dengan menit ke- $527,36 \%$ dan menit ke- 60 $46,62 \%$.

\section{DAFTAR PUSTAKA}

Febriyenti, F., Ben, E., \& Prima, T. (2013, October 4). Formulasi Mikrokapsul Glikuidon Menggunakan Penyalut Etil Selulosa dengan Metode Emulsifikasi Penguapan Pelarut. Prosisding Seminar Nasional Dan Workshop Perkembangan Terkini Sains Farmasi Dan Klinik 3. Seminar Nasional dan Workshop Perkembangan Terkini Sains Farmasi dan Klinik 3, Universitas Andalas, Padang.

Fellows, P. (2017). Food processing technology: Principles and practice (4th ed.). Woodhead Publishing/Elsevier Science, Netherlands.

Fennema, O. (1996). Food Chemistry. Marcell dekker Inc, New York.

Hardi, J., Citra, D., Syamsuddin, \& Pusptasari, D. J. (2020). Efisiensi Mikroenkapsulasi Ekstrak Kulit Buah Naga Super Merah (Hylocereus costaricensis) Tersalut Maltodekstrin Berdasarkan Kecepatan Pengadukan: KOVALEN: Jurnal Riset Kimia, $\quad 6(1):$ 1-8. 
https://doi.org/10.22487/kovalen.2020.v6.i 1.12647

Hardi, J., Sugita, P., \& Ambarsari, L. (2013). Dissolution Behavior, Stability And AntiInflammatory Activity Of Ketoprofen Coated Tripolyphosphate Modified Chitosan Nanoparticle. Indonesian Journal of Chemistry, 13(2): 149-157. https://doi.org/10.22146/ijc.21298

Idham, Z., Muhamad, I. I., \& Sarmidi, M. R. (2012). Degradation Kinetics and Color Stability of Spray-Dried Encapsulated Anthocyanins from Hibiscus Sabdariffa L. Journal of Food Process Engineering, 35(4): 522-542. https://doi.org/10.1111/j.17454530.2010.00605.x

Lachman, L., Lieberman, H., \& Kanig, J. (1994). Teori dan Praktek Farmasi Industri Edisi III. Universitas Indonesia Prees, Jakarta.

Laohasongkram, K., Mahamaktudsanee, T., \& Chaiwanichsiri, S. (2011). Microencapsulation of Macadamia oil by spray drying. Procedia Food Science, 1, 1660-1665.

https://doi.org/10.1016/j.profoo.2011.09.2 45

Molyneux, P. (2003). The use of the stable radical Diphenylpicrylhydrazyl (DPPH) for estimating antioxidant activity. 26.

Novaldi, N., Prismawiryanti, P., Hardi, J., \& Ys, H. (2019). Mikroenkapsulasi Ekstrak Ampas Jahe Merah Dari Hasil Pemisahan Minyak Jahe Merah. KOVALEN: Jurnal Riset Kimia, 5(1): 17-23. https://doi.org/10.22487/kovalen.2019.v5.i 1.14563

Nurliyana, R., Zahir, I., Suleiman, K., Aisyah, M. R., \& Kamarudin, K. R. (2010). Antioxidant study of pulps and peels of dragon fruits: $A$ comparative study. International Food Research Journal, 17(2): 367-375.

Putri, N. K. M., Gunawan, I. W. G., \& Suarsa, I. W. (2015a). Aktivitas Antioksidan Antosianin Dalam Ekstrak Etanol Kulit Buah Naga Super Merah (Hylocereus costaricensis) Dan Analisis Kadar Totalnya. JURNAL KIMIA, 9(2): 243-251.
Putri, N. K. M., Gunawan, I. W. G., \& Suarsa, I. W. (2015b). Aktivitas Antioksidan Antosianin Dalam Ekstrak Etanol Kulit Buah Naga Super Merah (Hylocereus costaricensis) Dan Analisis Kadar Totalnya. Jurnal Kimia (Journal of Chemistry). 9(2): 243-251. https://doi.org/10.24843/JCHEM.2015.v09 .i02.p15

Supriyadi, \& Rujita, S. (2013). Karakteristik Mikrokapsul Minyak Atsiri Lengkuas Dengan Maltodekstrin Sebagai Enkapsulan. Jurnal Teknologi Dan Industri Pangan, 24(2): 201.

Thies, C. (1996). A Survey of Microencapsulation proses. In microencapsulation. Mothods and Application. Marcel Dekker, New York (pp. 1-20).

Trojer, M A. (2012). Modification of microcapsules for controlled release. [Thesis for: Doctor of Philosophy]. Chalmers University of Technology, Sweden. 